Columbia Business School
Center on Japanese Economy and Business

CENTER ON JAPANESE ECONOMY AND BUSINESS

日本经济经営研究所

Working Paper Series

June 2016, No. 351

\title{
Four Types of Attitudes Towards Foreign Workers: Evidence from a Survey in Japan
}

Frances Rosenbluth, Rieko Kage, and Seiki Tanaka 


\title{
Four Types of Attitudes Towards Foreign Workers: Evidence from a Survey in Japan *
}

\author{
Rieko Kage $^{\dagger} \quad$ Frances Rosenbluth ${ }^{\ddagger} \quad$ Seiki Tanaka ${ }^{\S}$
}

June 30, 2016

\begin{abstract}
Employing a survey method to explore attitudes towards foreign workers in Japan, we uncover evidence that upends the conventional wisdom that "socio-tropic values" are anchored in perceptions of threat. Building a new typology that differentiates among native-born citizens who value or fear foreigners for their expected effects on the economic and cultural dimensions, we find that Japanese corporate managers, especially in labor-scarce sectors, appreciate the positive effects of foreign labor more than they dread the dilution of cultural beliefs and practices that underpinned the fabled Japanese labor force. This finding is significant because, even without becoming whole-hearted multi-culturalists, a positive disposition of Japanese corporate management towards foreign workers could signal a shift in policy. Although ethnocentrists remain in Japan (as elsewhere), the views of the business community are likely to have more bearing on government policy than those of other groups.
\end{abstract}

*The authors are listed in alphabetical order. We would like to thank Michael Thies for his comments. We also thank the Mitsubishi Foundation and the Murata Science Foundation for generously supporting this project. The human subject protocol of the research was evaluated and approved by the Institutional Review Board, Faculty of Arts and Sciences, University of Tokyo, and the research was conducted following the approval.

$\dagger$ University of Tokyo, email: kage@waka.c.u-tokyo.ac.jp.

$\ddagger$ Yale University, email: frances.rosenbluth@yale.edu.

$\S$ University of Amsterdam, email: seikitanaka@gmail.com. 


\section{Introduction}

Japan and Europe are sitting on a demographic time bomb: low birth rates are shrinking the ratio of taxpaying workers to social security recipients at a remarkable clip. Nevertheless, many citizens of rich countries are leery of expanding immigration to address this problem. Although Japan and Europe could easily swell their workforces with would-be foreign workers from their more populous or less prosperous neighbors, nowhere is opening the floodgates to immigration a popular idea. Individual attitudes towards immigration are generally negative across rich democracies. ${ }^{1}$ Figure 1 shows the percentage of respondents in the 2005-09 wave of the World Values Survey who believe in either imposing strict limits on immigrants coming to work in their countries, or in prohibiting people from coming to work altogether. According to the figure, Japanese attitudes towards immigration do not deviate starkly from those of other industrialized countries, but with one of the OECD's most rapidly aging demographic profiles and most restrictive immigration policies, Japan affords an excellent opportunity to interrogate the origins and tenacity of negative views towards foreigners.

Why are foreign workers unpopular? A growing body of empirical work casts doubt on economic self-interest alone. In a review of over 100 empirical studies including some of their own, Hainmueller and Hopkins (2014) have gone so far as affix the label of "zombie theory" to the idea that native citizens dislike foreign workers principally for fear of losing their jobs, facing lower wages, or having to pay out more taxes for low-wage, high-welfare-receiving foreigners. In place of the economic self-interest theory, a more amorphous notion of "socio-tropic values" has gained ground. ${ }^{2}$ The apparent preference, when faced with a choice among foreign workers, for educated, high status newcomers with strong language facility is taken to mean that native performances care about the

\footnotetext{
${ }^{1}$ Fetzer (2000); Pew Research Center (2014) - the Pew Report is available online at http://www . pewglobal.org/2014/05/12/chapter-3-most-support-limiting-immigration/.

${ }^{2}$ The term "socio-tropic" originates in social psychology where "sociotropy" refers to a personality trait tending towards dependence on interpersonal relationships as opposed to personal autonomy. Political scientists Donald Kinder and Rodney Kiewiet coined the phrase "socio-tropic voting" in their path breaking 1981 article to explain vote choices based on the economy's overall performance (Kinder and Kiewiet 1981); but there is less agreement as to motivations: do voters use aggregate economic performance as an information shortcut about how well they will fare individually; or does it reveal non-instrumental identification with the collective unit?
} 
country as a whole - that they are expressing collective rather than selfish values.

Figure 1: Baseline Attitude toward Immigration Policy by World Value Survey

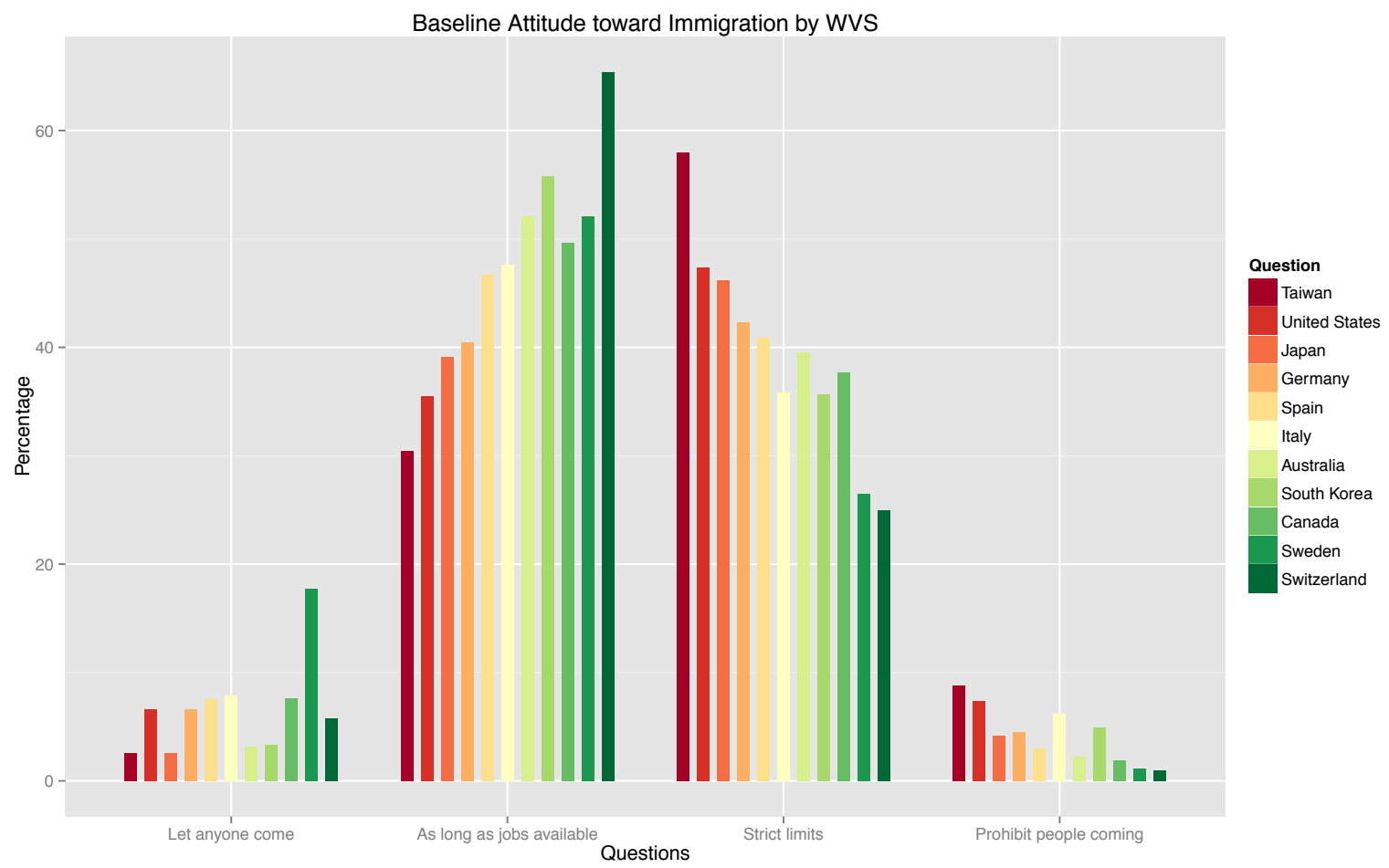

Note: Question wording: How about people from other countries coming here to work. Which one of the following do you think the government should do? The figure excludes the answers of "Missing," "No answer," and "Don't know."

Source: World Value Survey Wave 5 (2005-2009).

Untangling what "socio-tropic" preferences mean when it comes to immigration is an important next step for theoretical and practical reasons. Theoretically, it is unclear from current evidence whether socio-tropic immigration preferences are an information short cut for determining what is one's economic self-interest, an expression of a noninstrumental cultural value, a psychological aversion to poor people, or some combination. Practically, tighter causal knowledge is important for governments or other groups that may want to put together coalitions for less restrictive immigration policies for economic, humanitarian or other reasons.

This paper takes advantage of Japan's restrictive immigration policy to probe more deeply into the nature of socio-tropic preferences. Since few Japanese compete or expect to compete with foreign workers, Japanese voters generally do not oppose immigration for fear of their own jobs (Green and Kadoya 2015). Japanese citizens may nevertheless 
anticipate lower wage growth or future job insecurity as a result of new immigration. ${ }^{3}$

In our view, the socio-tropic preferences argument also suffers from one-sided conceptualization focusing on threats. The two principal impulses behind citizens' socio-tropic views are hypothesized to be feelings of economic or cultural loss. In the former, voters worry about fiscal burdens or lower wages economy-wide (Fetzer 2000, Quillian 1995). In the latter, natives fear that newcomers will spoil valued cultural beliefs and practices (Card, Dustmann and Preston 2012, Sides and Citrin 2007, Sniderman, Hagendoorn and Prior 2004). In both of these views, immigrants are viewed as undermining social assets of some kind; but what if at least some voters also perceive positive impacts of immigrants on society? In this paper, by extending the socio-tropic continuum in the positive direction, we propose stylized combinations of immigration bias to produce the following types: Integrators; Diversifiers; Exploiters; and Discriminators. As shown in Table 1, integrators associate immigrants with positive effects on both the economy and culture; Diversifiers appreciate immigrants' cultural assets but worry about negative economic impacts; Exploiters worry about negative cultural impacts while valuing economic ones; and Discriminators are negatively predisposed to immigrants on both economic and cultural grounds. We further argue that voters' socioeconomic status, in a probabilistic sense, predicts their type.

Table 1: Typology of interacted economic and cultural impacts

\begin{tabular}{|c|c|c|}
\hline & $\begin{array}{c}\text { High economic } \\
\text { appreciation }\end{array}$ & $\begin{array}{c}\text { Low economic } \\
\text { appreciation }\end{array}$ \\
\hline $\begin{array}{c}\text { High cultural } \\
\text { appreciation }\end{array}$ & Integrators & Diversifiers \\
\hline $\begin{array}{c}\text { Low cultural } \\
\text { appreciation }\end{array}$ & Exploiters & Discriminators \\
\hline
\end{tabular}

By means of a large, nation-wide survey, we examine correlates of attitudes towards immigrants or foreign workers in Japan to parse different motivations for supporting or

\footnotetext{
${ }^{3}$ Because there are relatively few foreign workers in Japan, many of the attitudes so far are based on hypothetical scenarios rather than personal experience or encounters (Allport 1954, Iyengar et al. 2013, Kobayashi et al. 2015).
} 
opposing immigration in Japan. ${ }^{4}$ Our survey results confirm that Japan currently has at least two patterns of anti-immigration bias: Exploiters and Discriminators. In line with previous work (Kinder and Kam 2009), we find that ethnocentric voters are more likely to show anti-immigrant bias. Further, we find that they perceive both economic and cultural threats. By contrast, we find that corporate leaders are more likely to be in favor of immigrants in spite of concerns about cultural dilution. Japanese business leaders seem to favor immigration for the sake to increased productivity and on condition that immigrants are not socially integrated.

\section{The Argument: Economic and Cultural Impacts}

Current debates about the nature of socio-tropic threat perceptions are dominated by an "economics versus culture" framing (Hainmueller and Hopkins 2014). On the one hand, survey respondents in rich democracies the world over tend to favor well-educated and skilled workers who they believe would add luster to their economies (Chandler and Tsai 2001, Hainmueller and Hopkins 2014, Hainmueller and Hiscox 2010, Iyengar et al. 2013, Sniderman, Hagendoorn and Prior 2004, Tingley 2013). Citizens with these views embrace the economy's best interests as far as they understand them, or they seek clues for their own well being in the economy as a whole. ${ }^{5}$

On the other hand, since most studies of the economic impacts of immigration suggest that immigrants do not harm local economies (Card 1990; 2001), natives may not discriminate against immigrants based on economic factors, but rather, based on cultural values. People may want to have neighbors and co-workers who share their language, ethnicity, culture, and religion (Card, Dustmann and Preston 2012). Sides and Citrin (2007) argue

\footnotetext{
${ }^{4}$ Due to the government's restrictive policy, Japan does not have many immigrants and Japanese voters are more familiar with the terms foreigners and foreign workers. This paper uses the words interchangeably, but our analyses focus mainly on foreign workers.

${ }^{5}$ As Dancygier and Donnelly (2013) and Dancygier and Walter (2015) point out, a preference for highskilled foreign workers by high-skilled natives is not necessarily a refutation of economic self-interest. High-skill jobs tend to be more specialized than low skill jobs, so that native doctors or computer programmers or scientists would likely benefit from foreign worker counterparts with complementary skills. Goldstein and Peters (2014, pp. 188) find, moreover, that although high-skill Americans are generally open to high-skill foreign workers, the Great Recession of 2008 turned many of them against immigration, presumably by increasing their sense of vulnerability.
} 
that people's bias toward immigrants depends on symbolic perceptions about immigrants, rather than actual conditions at the country level; in particular, they find that natives are more concerned about whether immigrants affect the value of cultural homogeneity and national identity. ${ }^{6}$ Similarly, Ivarsflaten (2005) finds that Western Europeans are concerned with cultural homogeneity and are concerned that cultural diversity will have a negative effect on their nation. Using an experimental approach, Sniderman, Hagendoorn and Prior (2004) find that considerations of national identity have greater impacts than economic considerations on people's attitudes toward immigrants and more opposition is observed if immigrants are not fitting in the host culture (see also Sniderman and Hagendoorn 2007). In sum, the cultural socio-tropic view posits that people are more likely to have anti-immigrant attitudes when immigrants pose a threat to the national identity or the traditional way of life (see also McDaniel, Nooruddin and Shortle 2011).

Despite their divergence, these two approaches agree on one point: immigrants are perceived as a threat. To consider possible positive economic impacts of immigrants, think of an "optimal" immigration level from a self-interested point of view. Neoclassical models of international asset flows posit that liberal immigration policies should increase productivity and drive up wages. A body of evidence shows, in fact, that foreign workers typically take jobs that natives do not want - for example, jobs that are low paying, dangerous, and/or dirty; or for which qualified natives are scarce (Card 2005; 2009, Card, Dustmann and Preston 2012). Low skilled foreign workers should free up homeborn workers to shift into more complex and communication-intensive professions for which foreigners are less competitive (Peri 2012; 2014). The lowest-skilled native workers appear to be the most vulnerable since manual labor is easily substitutable, but Ottaviano and Peri (2012) found that even for this most vulnerable group in the US over the period of 1990 to 2006, immigration to the US had at most a mildly negative long run effect, between $-3.1 \%$ and $-0.1 \%$ on real wages of the least educated natives. One reason for the negligible effect is that, given the free flow of capital and goods, low-wage foreign labor is often a substitute for moving production offshore where wages are cheaper, not

\footnotetext{
${ }^{6}$ They also argue that the misperception about the size of immigrants is an important predictor.
} 
a replacement for native workers. In a globally integrated economy, restricting foreign workers is no guarantee of stable wages or strong employment levels at home (Card 2001).

Cultural contributions of immigrants also are significant (Koopmans 2013). The United States has famously benefited from successive waves of immigrants in enriching its culture and, to some extent, in keeping the country demographically young. Cultural contributions may also amplify economic contributions. A substantial corpus of research suggests that diversity among decision makers produces systematically better judgments; and conversely, homogeneity of belief and experience is likely a liability in a kaleidoscopic world (see for example Apfelbaum, Phillips and Richeson 2014).

Whatever the objective reality, beliefs about the net contributions of immigration to native culture (and one's place in it) vary enormously. Survey evidence suggests that more educated respondents place greater value on cultural diversity (Card, Dustmann and Preston 2012, Citrin et al. 1997). We therefore reject the dichotomous "economic versus cultural threat" perspective in favor of a richer typology that considers the possibility of positive evaluations of immigration depending on the type of native-born citizens. Our goal in this paper is to identify the four types empirically - those that do and do not value immigration on the economic and cultural dimensions - and the reasons for their positions.

\section{Exploiter Attitudes}

Unlike in the U.S. where workers are readily hired or fired as employers adjust their quarterly performance, Japanese workers - at least those hired in "general track" positions in large corporations - are relatively secure. Japan's long-term labor contracts, which emerged from the competition for scarce labor in the economic booms following World War I and World War II, have become a remarkably durable part of Japan's social landscape despite repeated economic downturns (Song 2014). Even without pressure from strong unions or labor governments as in Europe, for these are absent in Japan, Japanese corporations have sought to protect their reputations as life-time employers for the sake of attracting and cultivating the best possible human capital (Moriguchi and 
Ono 2006, Pempel and Tsunekawa 1979).

Once in place, the lifetime employment system established a powerful set of incentive structures that shaped expectations about the meaning and evaluation of merit. An employer "stuck" with an employee for life is highly motivated to invest in that person's human capital to make that person as productive as possible. The employee, similarly, is motivated to invest in skills, often specific to the workings of that firm, in order to rise through the ranks as effectively as possible. Because lifetime employment implies job security but not equal rates of promotion, competition is channeled into performance as evaluated by a particular set of supervisors relative to a particular group of colleagues (Imada and Hirata 1995, Koike 1991). Employers could insist not only on people who contributed to the firm's bottom line, but also on people who did not challenge their authority. Stable hierarchy, with the attending ability to cultivate and choose those who make their jobs more pleasant, is a benefit to managers of the lifetime employment system.

The inability to shed abundant labor in cyclical or secular downturns could be fatal to firms in competitive markets. Japanese firms have famously dealt with these challenges in a variety of ways including wage flexibility through the use of bonuses; temporarily seconding workers to corporate subsidiaries at the bottom of the business cycle; and restricting lifetime contracts to a core subset of workers (Kagono and Kobayashi 1994, Koike 1983, Koshiro 1983). As Aoki (1988) points out, however, it is impossible to see Japan's long-term labor contracts in isolation from the limits on competition in Japan's financial markets, which enabled banks to make the long-term loans that underpinned stable employment arrangements. As Japan's financial markets became more competitive and fluid from the mid 1990s, Japanese corporations have had to reduce the percentage of their workforces encompassed in long-term contracts. This means that core workers in big firms will still enjoy lifetime employment, but a growing number of workers will be relegated to temporary or short-term contracts with less job security and uncertain benefits.

If Aoki is right, more fluid labor markets in Japan in the future will exert a powerful 
influence on both immigration policy and attitudes towards foreign workers, but not in the same direction. On the one hand, corporate managers who have to raise money on a fluid and competitive financial market will be under more pressure to reduce fixed labor costs, which will motivate them to rely more on cheaper and more flexible labor at home or abroad for at least some of their operations. We can expect corporate Japan to become, like corporate managers in the rest of the world, more favorable towards immigration and/or move more of their operations overseas. A corporate survey conducted by the government (Ministry of Health and Welfare 2016) reveals that labor shortages are observed across all sectors. From this, we expect corporate managers to be in favor of accommodating foreign workers in hoping that they will fill the labor shortage.

On the other hand, in many sectors of the economy, capital and labor remain relatively rigid in Japan. Because many employers have been able to maintain a high-quality and loyal workforce, the Japanese business community has not yet become champions of imported labor to the degree that, for example, American business tends to favor liberal immigration. We take this to be the principal reason for Japanese firms' support for a restrictive immigration policy, and a mechanism for the reinforcement of "traditional" Japanese values. Japanese corporations, which have made a virtue of Japan's cultural values such as "hard work," "fitting in," and "respect for authority," face relatively little challenge to these values from a more free-wheeling entrepreneurial sector placing a bigger premium on "anti-authoritarianism," "creativity," and "merit." To the extent that this is the case, we should expect that corporate mangers should continue to enjoy "managerial rents" from a culturally docile, domestic work force (Burns and Gimpel 2000, Citrin et al. 1997, Kinder and Kam 2009, Sides and Citrin 2007, Sniderman, Hagendoorn and Prior 2004, Valentino, Brader and Jardina 2013).

Hypothesis: Corporate managers expect foreign workers to benefit the economy but they do not value cultural diversity.

The seemingly conflicting preferences of corporate managers can be reconciled if cor- 
porate managers just want to exploit cheap foreign workers. Corporate managers cannot expect that foreign workers will be fully integrated to Japan and become a complete substitute of Japanese general track workers right away. But if they start perceiving that foreign workers can also be general track workers in the future, they may adopt the "Integrator" rather than "Exploiter" attitude towards immigrants.

\section{The Survey}

\section{Survey Design}

To examine our hypotheses, we undertook an original survey in Japan with a nationally representative sample of 4,236 Japanese adults between April 15 and 25, 2016. The sample was drawn by a Japanese survey firm, Nikkei Research, from their opt-in online panel. ${ }^{7}$ It is a non-probability sample, but we endeavored to make the sample close to the general population by weighting demographic variables of age, gender and residential locations in the direction of representativeness. ${ }^{8}$

The survey consists of basic demographic questions, key covariates including general attitudes towards foreign workers and other relevant measures such as personality traits. Although there are several existing surveys that ask attitudes towards foreign workers, our survey is unique in the sense that it can fill two key shortcomings of existing data. First, due to the Japanese government's restrictive immigration policy, it is almost impossible for foreign workers to become Japanese citizens after arriving in Japan for work and stay permanently. Still, some respondents may associate the words "immigrants" or "foreign workers" with foreigners with permanent resident status (e.g., Japanese Koreans and Japanese Brazilians). Accordingly, there is a reasonable concern that simply asking attitudes towards "foreigners" may increase measurement errors, thereby leading to biased estimators: some people answer the questions thinking of short-term foreigners, while others think of long-term foreigners.

\footnotetext{
${ }^{7}$ The respondents were invited to participate in our survey by Nikkei Research and answered the questions on our Qualtrics survey website.

${ }^{8}$ This paper does not use a sampling weight to adjust the remaining imbalances.
} 
Second and relatedly, existing surveys do not differentiate among foreigners' countries of origin, which also generates measurement error. For example, the Japan General Social Survey (JGSS) run by the Osaka University of Commerce, similar to the American General Social Survey and European Social Survey, collects data on a variety of social indicators including attitudes towards foreign workers, but the latest survey JGSS-2015 simply asks whether respondents agree with an increase in "foreigners" (gaikokujin) in their community. ${ }^{9}$

To overcome these limitations, we focus on short-term foreign workers for the purposes of this paper. We also asked who respondents think of when they talk about short-term (or long-term) foreign workers, asking them to select a country/region of origin from the following: China, Korea, Taiwan, Southeast Asia, Brazil, Brazil (Japanese Brazilians), Europe, and United States. By controlling for this variation in respondents' perceptions about "foreigners," we aim to reduce measurement errors and improve our inference.

The sensitivity of the topic may undermine the validity of survey data, since respondents may hesitate to reveal truthful views for fear of incurring negative judgments by the surveyors. To deal with this well known problem of possible self-censorship, we follow Berinsky (2004) and Berinsky and Lavine (2012) and ask three questions that measure trait susceptibility to social desirability bias - some people may be more likely to answer the questions in a socially desirable manner ${ }^{10}$ - and then control for respondents' self-monitoring tendency in our analyses.

Finally, our pilot study prior to the current survey revealed that most Japanese citizens do not have experience interacting with foreigners and have not thought much about immigration issues. We therefore employed a prime before asking general attitudes toward foreign workers so that respondents could better imagine what it would be like to have more immigrants. We used two hypothetical scenarios that a respondent could face if Japan admitted more foreign workers. In the first scenario, we asked "How would you

\footnotetext{
${ }^{9}$ Additionally, existing surveys do not specify how many foreigners they are talking about in their surveys. It is possible that some people may not want to accommodate foreigners in general but they can agree to accommodate a small number of foreigners for some reason.

${ }^{10}$ The three items are: (1) I have trouble changing my behavior to suit different people and different situation; (2) I put on a show to impress or entertain others; and (3) In a group of people, I am often the center of attention.
} 
feel in the following scenario: you broke your leg in a car accident and went to a hospital, but found out that you have to wait for two hours before your treatment because two short-term foreign workers are ahead of you." The second scenario asked, "How would you feel if you lost your job because of a short-term foreign worker?" After the prime, we asked respondents' general attitudes towards liberalizing entry for foreign workers. We describe our key variables in greater detail below.

\section{Data}

\section{Dependent variables}

To evaluate general attitudes toward foreign workers, following previous work (Green and Kadoya 2015, Nagayoshi 2009), we use the Immigration-positive variable as our main dependent variable. But unlike the previous work that uses the JGSS data that are vague about how many new foreigners would be admitted, we asked specifically about how many immigrants should be admitted. We asked respondents to answer the question on a four-point scale: (1) "No new worker entry at all or a decrease from the current number"; (2) "Maintain status quo"; (3) "Admit fewer than 1.5 million foreign workers"; and (4) "Admit more than 1.5 million foreign workers." ${ }^{11}$ Following previous work (Green and Kadoya 2015, Nagayoshi 2009), we then recoded the variable on a binary scale: (0) against admitting more foreigners; and (1) in favor of admitting more foreigners.

\section{Independent variables}

To examine our expectation about corporate managers' preferences, we used the Japanese Standard Classification of Occupations (JSCO), similar to International Standard Classification of Occupations (ISCO). We created a binary variable to capture those that are corporate managers or not. We expect that corporate managers understand the economic merits of admitting foreign workers, but are hesitant about the dilution of cultural values, for corporate Japan as a whole and perhaps specifically for themselves as managers on a hierarchical ladder.

\footnotetext{
${ }^{11}$ We provided an actual information of how many foreign workers exist in Japan: about $1.1 \mathrm{M}$ shortterm foreign workers (about 1 in 100 is a foreigner in Japan).
} 
To examine other labor market effects on respondents' attitudes, we consider the following four variables. First, we identified three major sectors that are in the most need for more workers: the financial sector, medical sector, and restaurant sector (Ministry of Health and Welfare 2016). In combination with the JSCO occupation classification data, we then created binary variables flagging if a respondent does or does not belong to one of those sectors.

Employment status is another obvious consideration in determining attitudes towards foreigners who could be potential competitors. Unemployed respondents should be less favorable towards foreign workers, all else equal.

We capture the usual battery of demographic data with possible relevance to attitudes towards foreign workers: respondents' age, gender, household income, and level of education. Additionally, we include a political variable to code as 1 if a respondent is a supporter of the conservative incumbent political party, Liberal Democratic Party.

To consider the effects of interacting with foreigners, we use three contact theory variables: Foreign friend; Past interactions; and Perceived number of foreigners. The Foreign friend asks how many foreign friends the respondents have. The Past interactions variable measures how much experience respondents have in interacting with foreigners in their social life; it is coded to run from 0 to 1 , where higher values indicate more experience. The Perceived number of foreigners variable captures whether respondent see foreigners in their community. We expect that those who are high in these contact theory variables will be more supportive of increasing the number of foreign workers.

One more attribute we seek to measure is ethnocentrism a general form of prejudice that tends to predict anti-immigration attitudes (Kinder and Kam 2009). We use Kinder and Kam (2009)'s ethnocentrism scale because it captures broadly defined prejudice rather than negative attitudes towards a specific out-group. More specifically, we use the feeling thermometer ratings of Japanese people and people from other countries. Ethnocentrism thus consists of thirteen items (feeling thermometer ratings of Japanese and twelve foreign groups) and is coded to run from 0 to 1 , where higher values indicate 
an endorsement of ethnocentrism. ${ }^{12}$

Research suggests that ethnocentrism is strongly associated with an authoritarian personality (Kinder and Kam 2009). We therefore also include Right-wing authoritarianism $(R W A)$ that consists of five items and is coded onto a 0-1 scale, where the higher values correspond to greater endorsement of authoritarianism. ${ }^{13}$

\section{Variables to check mechanisms}

To examine mechanisms through which respondents arrive at their views towards foreigner workers, we asked separate questions about what kinds of effects on Japanese society they expect to see if Japan were to admit more foreign workers. ${ }^{14}$ In line with the literature, we differentiated between economic and cultural effects. We asked about possible effects of foreign workers on labor market competition and fiscal constraints, about possible dilution of Japanese homogeneity, and about expected crime rates. Based on the questions, the current analyses use a binary measure to test the mechanisms: Economic effects code as 1 if respondents expect foreign workers to complement Japanese workers or to do dirty jobs in the place of Japanese who tend to avoid those jobs; ${ }^{15} 0$ otherwise; and Cultural effects code as 1 if respondents expect foreign workers to increase diversity

\footnotetext{
${ }^{12}$ The feeling thermometer scale asks respondents how they feel about groups in society. The question is the following: "We would like to get your feelings about some groups in Japanese society. When you see the group, please rate it with what we call a feeling thermometer by typing a number from 0 to 100 . On this feeling thermometer, a rating at 0 at degree means that you do not feel favorably toward the group. A rating at 100 degree means that you feel favorably and warm toward the group. If you do not feel particularly warm or cold toward a group, you would rate them at 50 degrees." We create the measure of ethnocentrism by taking the average of the twelve out-group thermometers and subtracting them from the in-group thermometer (i.e. Japanese).

${ }^{13}$ The five items were used to create a single RWA scale by using a factor analysis. Respondents were asked to answer each item on a five-point scale of agree strongly, agree somewhat, neither agree nor disagree, disagree somewhat, or disagree strongly. Five items are: (1) Some of the worst people in our country nowadays are those who do not respect our flag, our leaders, and the normal way things are supposed to be done; (2) A lot of our rules regarding modesty and sexual behavior are just customs which are not necessarily any better or holier that those which other people follow; (3) Students in high school and university must be encouraged to challenge their parents' ways, confront established authorities, and in general criticize the customs and traditions of our society; (4) The sooner we get rid of the traditional family structure, where the father is the head of the family and the children are taught to obey authority automatically, the better; and (5) It is always better to trust the judgment of the proper authorities in government and religion than to listen to the noisy rabble-rousers in our society who are trying to create doubts in people's minds.

${ }^{14}$ Throughout the current survey, we provided a specific number when we talk about the size of foreign workers. Here, we used 1.5 million foreign workers and we told respondents that after accommodating 1.5 million foreign workers, two out of 100 in a community, instead of one out of 100, become foreigners.

${ }^{15}$ Here, we mean "three D" jobs: the dirty, demanding and dangerous.
} 
and/or not dilute Japanese culture; 0 otherwise. It is important to note that the questions asked specifically about the effects on society, not on respondents themselves. All the variables are normalized to run from 0 to 1 , to enable comparison among coefficients within and across models. Table 2 provides summary statistics for the variables in the analyses.

Table 2: Summary Statistics

\begin{tabular}{lccccc}
\hline \hline VARIABLES & $\mathrm{N}$ & Mean & Std. Dev. & Min & Max \\
\hline Immigration-positive & 4,236 & 0.540 & 0.498 & 0 & 1 \\
Economic effects & 4,125 & 0.281 & 0.450 & 0 & 1 \\
Cultural effects & 3,997 & 0.125 & 0.331 & 0 & 1 \\
Age & 4,236 & 0.480 & 0.249 & 0 & 1 \\
Male & 4,236 & 0.472 & 0.499 & 0 & 1 \\
LDP & 4,236 & 0.225 & 0.417 & 0 & 1 \\
College or above & 4,236 & 0.565 & 0.496 & 0 & 1 \\
Income & 4,236 & 0.415 & 0.299 & 0 & 1 \\
Unemployed & 4,179 & 0.194 & 0.396 & 0 & 1 \\
Ethnocentrism & 4,236 & 0.528 & 0.126 & 0 & 1 \\
Self-monitoring & 4,236 & 0.381 & 0.200 & 0 & 1 \\
RWA & 4,236 & 0.458 & 0.158 & 0 & 1 \\
Corporate managers & 4,236 & 0.0446 & 0.206 & 0 & 1 \\
Medical sector & 4,236 & 0.00897 & 0.0943 & 0 & 1 \\
Restaurant sector & 4,236 & 0.0241 & 0.153 & 0 & 1 \\
Finance sector & 4,236 & 0.00732 & 0.0852 & 0 & 1 \\
Foreign friend & 4,236 & 0.293 & 0.455 & 0 & 1 \\
Past interactions & 4,236 & 0.526 & 0.499 & 0 & 1 \\
Perceived number of foreigners & 4,236 & 0.350 & 0.247 & 0 & 1 \\
\hline
\end{tabular}

Before turning to our regression analyses, we first provide an overview of some descriptive statistics. At first glance, looking at our main dependent variable, Immigrationpositive, our survey data show that $54 \%$ of the respondents are in favor of admitting more short-term foreign workers, while $46 \%$ are against. The number is higher than other similar survey data such as JGSS; for example, according to the JGSS-2010, 37\% of the respondents are in favor of admitting more foreigners. Several reasons can explain the difference including the later date of our sample, but it is important to note our narrower survey target: "foreign workers" rather than JGSS's catch-all category of "foreigners." 
We also asked the question about respondents' feelings towards foreign workers after the two priming scenarios. In response to the scenario questions, $66.6 \%$ of those surveyed answered that they would not resent foreign workers even if the foreign workers took their job; and an overwhelming majority of $91.8 \%$ answered that they would not resent foreign workers ahead of them in line for medical treatment.

\section{Findings}

\section{Baseline Analysis}

We now turn to an examination of what accounts for the variation among respondents in their attitudes towards short-term foreign workers. Figure 2 presents our baseline results. Given the binary scale of the dependent variable, the current analysis uses logit model. First, among the labor market variables, we find that corporate managers tend to be supportive of an increase in foreign workers. Workers in the labor-scarce finance sector are also more supportive of admitting foreign workers. Somewhat surprisingly, the Unemployment variable is not statistically significant at the $5 \%$ level, but along with the non-findings of the Medical sector and Restaurant sector, this may reflect the extraordinarily small numbers of foreigners currently in these sectors and a confidence (self-aware or not) that the government will continue with its restrictive immigration policy.

Most of the socioeconomic variables are not statistically significant, but we find that older people tend to be more hostile towards foreign workers. Consistent with previous studies in the U.S. (Kinder and Kam 2009), we find that ethnocentric respondents are more likely to oppose foreign entry. In fact, the Ethnocentrism variable is the strongest single predictor of respondents' attitudes towards foreign workers - increasing the value of Ethnocentrism from its 25 th to its 75 th percentile while holding other variables at their median decreases the likelihood of accommodating foreign entry by $13.1 \%$.

Among the contact theory variables, we find that only the Past interactions is statistically significant, suggesting that respondents who have experience interacting with 
foreigners are more supportive of admitting foreign workers. The Perceived number of foreigners variable is not statistically significant at the $5 \%$ level, but this is unsurprising given how few foreigners lived in Japan at the time of the survey. Finally, which foreigners come to mind when they think of foreign workers is somewhat important. Respondents who think of foreign workers from Southeast Asia tend to have more positive views towards foreign workers relative to other groups of foreign workers.

Figure 2: Determinants of Individual Preference for Increase in Foreign Workers

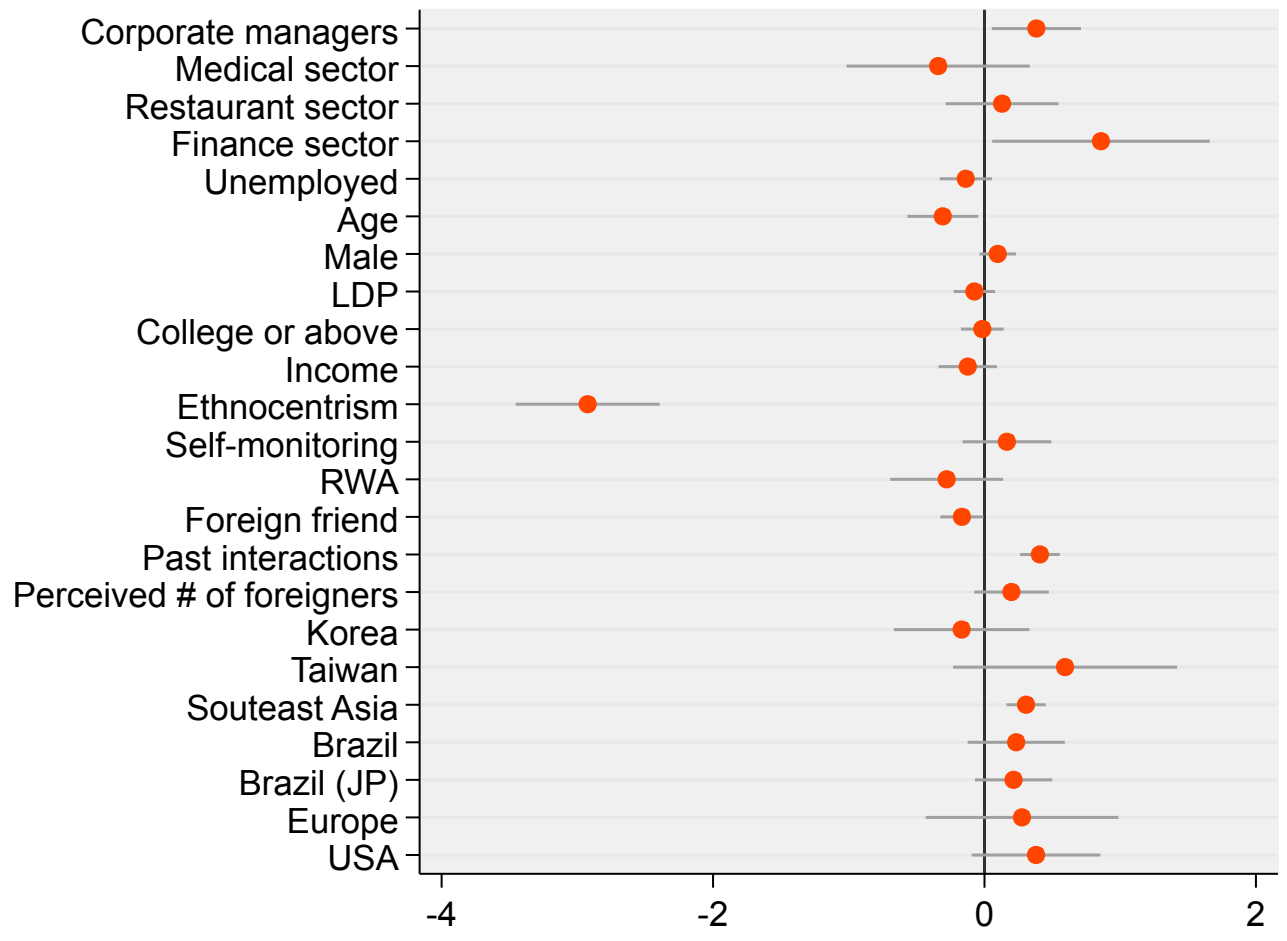

Note: We dropped several respondents from the analysis due to their inconsistent responses. As a result, the current analysis uses 4,179 observations. The horizontal bars indicate $95 \%$ confidence intervals.

\section{Mechanism Checks}

To understand more fully why some people favor increasing the number of foreign workers, we examine what various respondents think about the likely effects of foreign workers on Japanese society. Figure 3 reports the logit model analyses based on our mechanism check variables: we simply switch dependent variables from Accommodation willingness to Economic effects and Cultural effects. The red dots show coefficients for 
the model using the Economic effects and the blue dots show one for the model with Cultural effects. If a variable (such as the $L D P$ ) is significant in both models, it should suggest that LDP supporters are concerned with both economic and cultural effects; or if the variable is significant at only one of the models, it suggests that LDP supporters are concerned with only one of the aspects when they think about how foreign workers will affect society.

Figure 3: Mechanisms: Economic and Cultural Effects

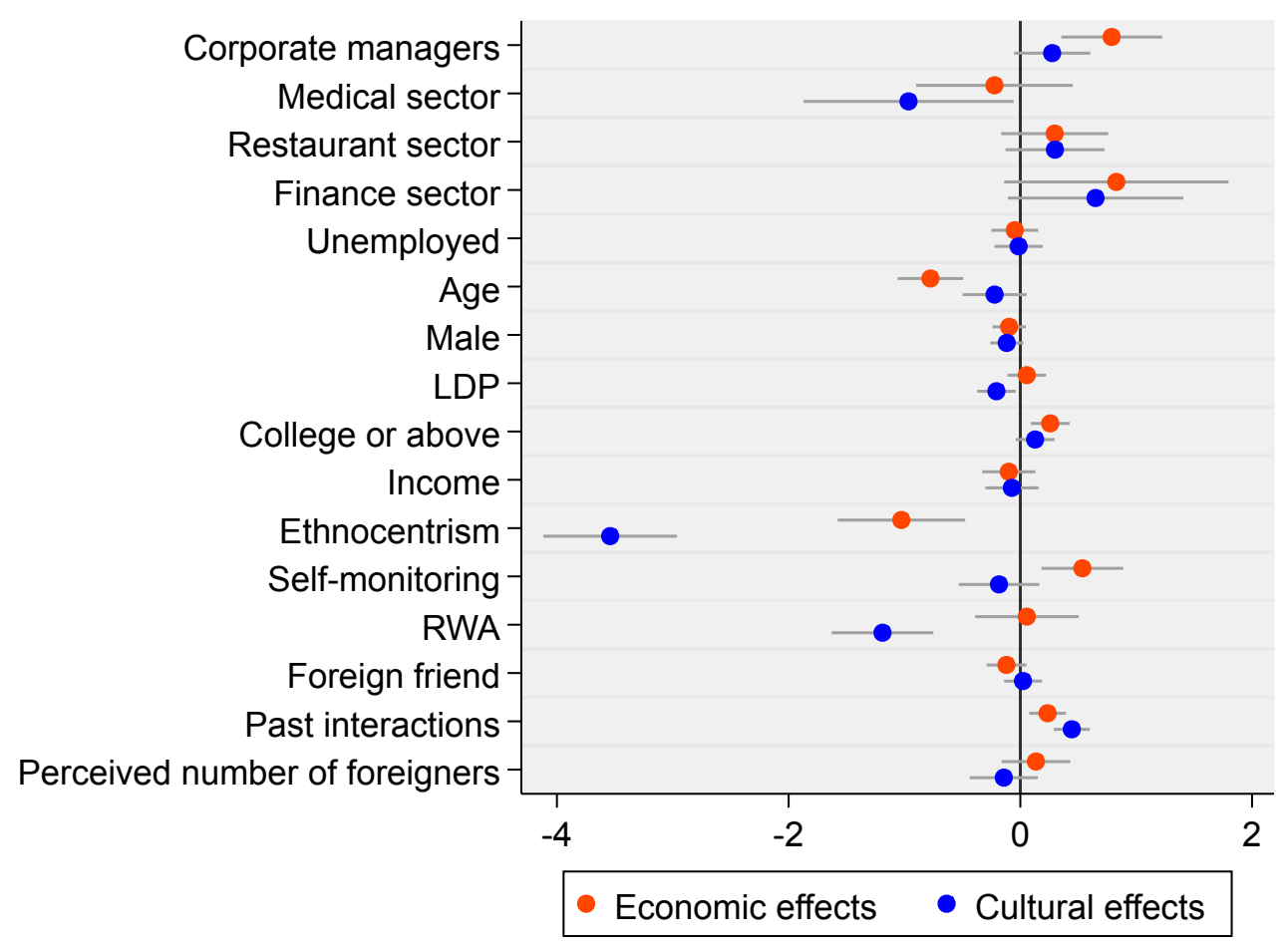

Note: We dropped several respondents from the analysis due to their inconsistent responses. As a result, the current analysis uses 4,179 observations. The variables for countries of origin are not reported. The horizontal bars indicate $95 \%$ confidence intervals.

First, we find that corporate managers are concerned principally with increased productivity. They expect that foreign workers will have positive effects on the economy, but they are more or less indifferent to cultural effects. They appear to be relatively unworried about the dilution of valued cultural beliefs and practices such as respect for (their) authority, either because they recognize the value of diversity, or because they are confident that they can control the flow of workers to maintain their favored cultural equilibrium. 
When it comes to respondents who are employees, we find that workers in the medical sector are not concerned with economic effects of foreign workers, but appear to worry about negative cultural effects. Perhaps this is due to the fact that an increase in foreign workers would increase the chances that they would have to treat foreign workers at their facility, and they worry about the language barrier.

Contrary to our expectations, older people, all else equal appear to be more concerned about negative economic than cultural effects of foreign workers. LDP supporters, on the other hand, are more worried about cultural dilution. Ethnocentric respondents worry about both negative economic and cultural effects but especially the latter. They share that concern with respondents who score high in the right-wing authoritarian tendency.

Respondents who tend to be susceptible to social desirability bias are more likely to expect positive economic effects of admitting more foreign workers, but not cultural impacts. We do not have an explanation for that tendency but it strikes us as an interesting finding for anthropologists of Japan to take up. As we expected, respondents who have experience in interacting with foreigners tend to expect both economic and cultural benefits from more foreigners.

We now combine the Economic effects and Cultural effects variables with our main dependent variable, Immigration-positive, and examine how much of the respondents' expectations about economic and cultural effects account for general attitudes towards admitting foreign workers. In the current analysis, we focus on the Corporate managers and Ethnocentrism variables that have been statistically significant across models.

We investigate the mechanisms using an algorithm proposed by Imai, Keele and Tingley $(2010)^{16}$ which places mediation analysis in a potential outcome framework to identify the indirect effects or average causal mediated effects (ACME). We first estimate models for the observed outcome and mediators, then simulate model parameters from the sampling distribution, and then the potential values of the mediator, and the potential outcomes given the simulated values of the mediator, before computing causal mediation effects. We are interested to know how corporate manager status as a treatment variable

\footnotetext{
${ }^{16}$ See also Imai, Keele, Tingley and Yamamoto (2011)
} 
(or those who are more than the median value in ethnocentrism) operates through each of two mediators: economic effects or cultural effects. Because each of the mediators is an observational variable, we included the same control variables as in Figure 2.

Given the binary nature of the mediating variables (Economic effects and Cultural effects), we use logit models for the first stage of the analysis to estimate the effects of the treatment on each mediator. We employ logit models for the overall analysis since our Immigration-positive measure is also binary. Table 3 reports the estimates of the indirect effects of each mediator ("ACME" on the far left of the table) and how much of the mediator accounts for the total effect of the Corporate managers and Ethnocentrism variables ("\% of Total via ACME" on the far right of the table).

Table 3: Mediation analysis

\begin{tabular}{ccccc}
\hline \hline & ACME & Direct effect & Total effect & $\begin{array}{c}\text { \% of Total } \\
\text { via ACME }\end{array}$ \\
\hline Treatment: & Corporate managers & \\
Economic effects & $0.046^{* *}$ & 0.045 & 0.091 & $50.1 \%$ \\
Cultural effects & 0.016 & 0.069 & 0.087 & $18.5 \%$ \\
\hline & Treatment: & Ethnocentrism & \\
Economic effects & $-0.043^{* *}$ & -0.565 & -0.611 & $7.0 \%$ \\
Cultural effects & $-0.187^{* *}$ & -0.474 & -0.599 & $31.1 \%$ \\
\hline
\end{tabular}

Note: We dropped several respondents from the analysis due to their inconsistent responses. As a result, the current analysis uses 4,179 observations.

The table shows that corporate managers care consistently about economic effects of foreign workers on society when deciding whether to support an increase in foreign workers. We find that the economic consideration accounts for a quite large portion in the decision: $50.1 \%$ of the total effect on their support to increase foreign workers. By contrast, we do not find statistically significant indirect effects through expected cultural effects, and the magnitude of the indirect effect is relatively small, $18.5 \% .{ }^{17}$

\footnotetext{
${ }^{17}$ This result is consistent with an analysis in Figure A of the Appendix, where we analyze what determines ethnocentrism. We find that corporate mangers are more ethnocentric, despite their preference for accommodating more foreign workers.
} 
To further reveal corporate managers' preferences, we take advantage of variation in perceived countries of origin. (Note that respondents think of different groups of foreign workers when they answer questions.) More specifically, we create two opposing groups in terms of human capital: Asian workers as the "cheap" labor group (including China and Southeast Asia) and Western workers as the "expensive" labor group (including Europe and the U.S.), and examine how corporate managers' expectations differ in terms of economic and cultural impacts by these two groups.

Figure 4 shows the results of this analysis. The red bars show how many corporate managers who think of Asian workers, on average, expect positive economic effects (leftside) and how many corporate managers who think of European workers expect the same (right-side). The blue bars show the same but use the cultural effects variable. Interestingly, both Asian and European groups show high scores in terms of economic effects, and this indicates that corporate managers generally think that foreign workers would benefit the economy.

However, when we look at their expectations about cultural effects, the figure reveals that many corporate managers worry about Asian foreign workers but not Western workers. This result suggests that corporate managers want to increase the number of foreign workers because they expect that they will bring economic benefits to the society despite concerns about possible cultural effects. One possible inference is that corporate managers would want to exploit short-term foreign workers such as those from China and Southeast Asia, and hope that they would return to their country of origin.

Respondents whom we identified as ethnocentric based on their answers generally oppose an increase in foreign workers because of both cultural and economic reasons. They are consistently concerned with economic and cultural threats when deciding whether or not to admit more foreign workers (See Table 3). We find that the cultural consideration accounts for a quite large portion in their decision: $31.1 \%$ of the total effect on their opposition to an increase in the number of foreign workers. The indirect effect through expected economic effects is relatively small, $7 \%$. 
Figure 4: Perception of Corporate Managers: Breakdown by Foreign Workers' Country of Origin

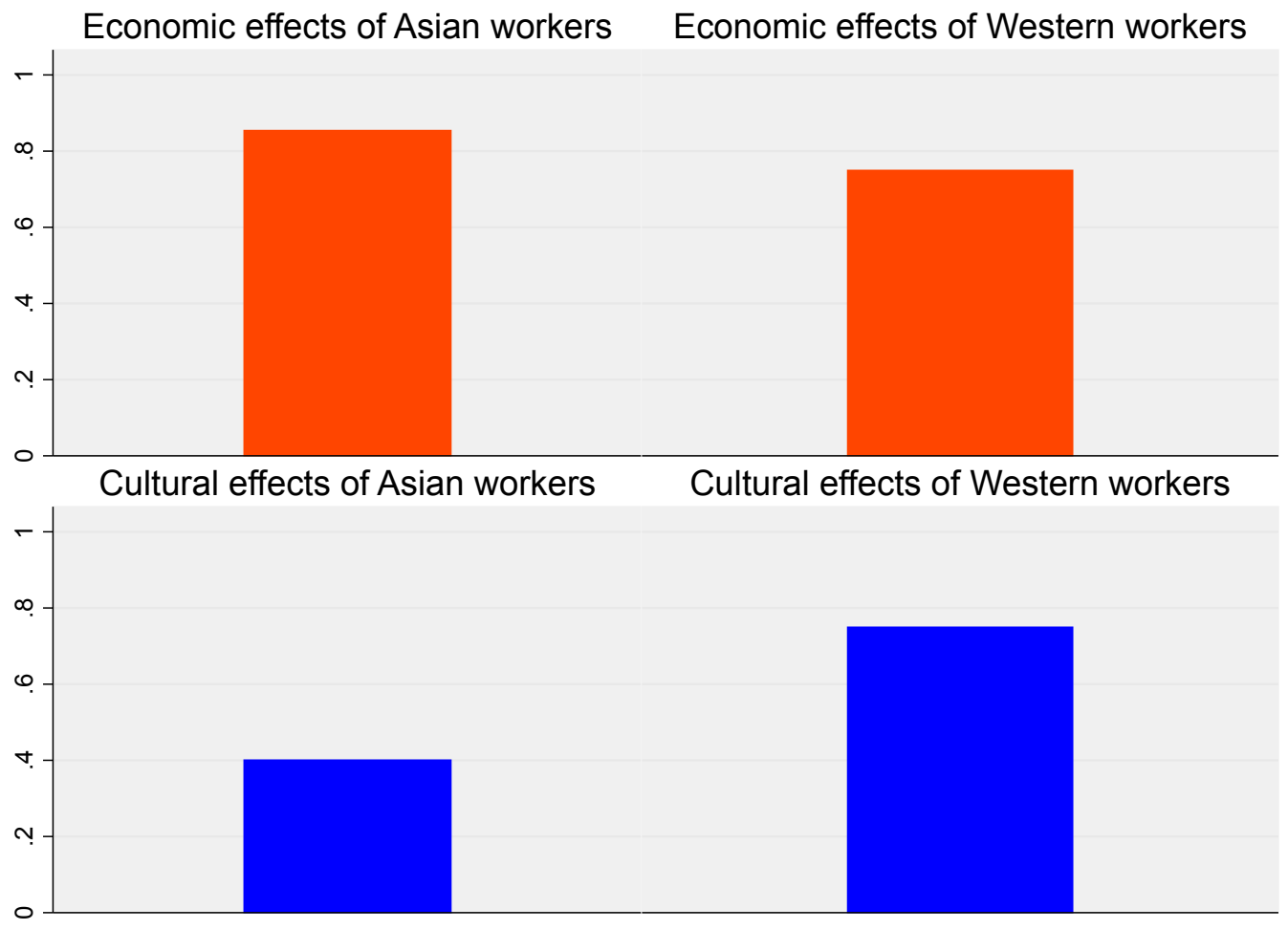

Note: We dropped several respondents from the analysis due to their inconsistent responses. As a result, the current analysis uses 4,179 observations. The horizontal bars indicate $95 \%$ confidence intervals.

\section{Conclusion}

This paper makes two principal contributions, one theoretical and one empirical. On the theory side, we suggest a new typology of socio-tropic values that considers respondents' expectations of positive as well as negative effects of more foreigners in society. Pitting arguments based on economic values against those based on cultural values to explain attitudes towards foreign workers is likely to be unproductive. We presented, instead, a way to think about how they are connected to arrive at positive, negative, or ambivalent conclusions about foreigners.

In Japan, where stable bank-firm ties since World War II have underpinned longterm labor contracts, "working hard" and "fitting in" have been extremely effective social values for Japanese workers in these firms. That is not to say that everyone in these jobs 
was happy - personal happiness is a different thing altogether. But these values were a reasonably good heuristic for how to achieve career success in a big corporation. Foreign workers who bring a variety of alternative values could throw off balance the stable hierarchies and firm loyalty that lubricated this well-functioning machine. However, due to pressing needs for cheap labor, corporate managers' cross-cutting preferences nets out to a favorable view towards more foreign workers. Businesses themselves have been reluctant to dilute the social values and practices that created a docile and loyal workforce. But if the business community becomes a champion of greater openness to foreign workers, Japanese policy could change dramatically.

Indeed, our study also shows that corporate managers think in markedly different ways than the rest of society. While existing studies have debated whether economic or cultural concerns drive individual attitudes towards foreign workers, our evidence suggests that "where you stand depends on where you sit." Corporate managers are more likely to be sensitive to economic concerns than is the general public. And although business leaders comprise a small slice of society, it is possible their greater policy influence could win out over xenophobia. 


\section{References}

Allport, Gordon W. 1954. The Nature of Prejudice. Reading, MA: Addison-Wesley.

Aoki, Masahiko. 1988. Information, Incentives and Bargaining in the Japanese Economy. New York: Cambridge University Press.

Apfelbaum, Evan, Katherine W. Phillips and Jennifer A. Richeson. 2014. "Rethinking the Baseline in Diversity Research Should We Be Explaining the Effects of Homogeneity?" Perspectives on Psychological Science 9(3):235-244.

Berinsky, Adam J. 2004. "Can We Talk? Self-presentation and the Survey Response." Political Psychology 25(4):643-659.

Berinsky, Adam J. and Howard Lavine. 2012. Self-Monitoring and Political Attitudes. In Improving Public Opinion Surveys: Interdisciplinary Innovation and the American National Election Studies, ed. John H. Aldrich and Kathleen M. McGraw. Princeton, NJ: Princeton University Press pp. 29-45.

Burns, Peter and James G. Gimpel. 2000. "Economic Insecurity, Prejudicial Stereotypes, and Public Opinion on Immigration Policy." Political Sience Quarterly 115(2):201-225.

Card, David. 1990. "The Impact of the Mariel Boatlift on the Miami Labor Market." Industrial and Labor Relations Review 43(2):245-257.

Card, David. 2001. "Immigrant Inflows, Native Outflows, and the Local Labor Market Impacts of Higher Immigration." Journal of Labor Economics 19(1):22-64.

Card, David. 2005. "Is the New Immigration Really so Bad?" Economic Journal 115(507):300-323.

Card, David. 2009. "Immigration and Inequality." American Economic Review 99(2):1-21.

Card, David, Christian Dustmann and Ian Preston. 2012. "Immigration, Wages, and Compositional Amenities." Journal of the European Economic Association 10(1):78119. 
Chandler, Charles R. and Yung-mei Tsai. 2001. "Social Factor Influencing Immigration Attitudes: An Analysis of Data From the General Social Survey." Social Science Journal 38(2):177-188.

Citrin, Jack, Donald P. Green, Christopher Muste and Cara Wong. 1997. "Public Opinion toward Immigration Reform: The Role of Economic Motivations." Journal of Politics $59(3): 858-881$.

Dancygier, Rafaela M. and Michael J. Donnelly. 2013. "Sectoral Economies, Economic Contexts, and Attitudes toward Immigration." Journal of Politics 75(1):17-35.

Dancygier, Rafaela M. and Stefanie Walter. 2015. Globalization, Labor Market Risks, and Class Cleavages. In The Politics of Advanced Capitalism, ed. Pablo Beramendi, Silja Häusermann, Herbert Kitschelt and Hanspeter Kriesi. Cambridge: Cambridge University Press.

Fetzer, Joel S. 2000. "Economic Self-interest or Cultural marginality? Anti-immigration sentiment and Nativist Political Movements in France, Germany and the USA." Journal of Ethnic and Migration Studies 26(1):5-23.

Goldstein, Judith L. and Margaret E. Peters. 2014. "Nativism or Economic Threat: Attitudes Toward Immigrants During the Great Recession." International Interactions 40(3):376-401.

Green, David and Yoshihiko Kadoya. 2015. "Contact and Threat: Factors Affecting Views on Increasing Immigration in Japan." Politics \& Policy 43(1):59-93.

Hainmueller, Jens and Daniel J. Hopkins. 2014. "Public Attitudes Toward Immigration." Annual Review of Political Science 17:225-249.

Hainmueller, Jens and Michael J. Hiscox. 2010. "Attitude towards Highly Skilled and Low Skilled Immigration: Evidence from a Survey Experiment." American Political Science Review 104(1):61-84. 
Imada, Sachiko and Shuichi Hirata. 1995. White-Collar no Shoushin Kozo /Promotion Strucures for White-Collar Workers]. Tokyo: The Japan Institute of Labour.

Imai, Kosuke, Luke Keele and Dustin Tingley. 2010. "A General Approach to Causal Mediation Analysis." Psychological Methods 15(4):309-334.

Imai, Kosuke, Luke Keele, Dustin Tingley and Teppei Yamamoto. 2011. "Unpacking the Black Box of Causality: Learning about Causal Mechanisms from Experimental and Observational Studies." American Political Science Review 105(4):765-789.

Ivarsflaten, Elisabeth. 2005. "Threatened by Diversity: Why Restrictive Asylum and Immigration Policies Appeal to Western Europeans." Journal of Elections, Public Opinion and Parties 15(1):21-45.

Iyengar, Shanto, Simon Jackman, Solomon Messing, Nicholas Valentino, Toril Aalberg, Raymond Duch, Kyu S. Hahn, Stuart Soroka, Allison Harell and Tetsuro Kobayashi. 2013. "Do Attitudes about Immigration Predict Willingness to Admit Individual Immigrants? A Cross-National Test of the Person-Positivity Bias." Public Opinion Quarterly $77(3): 641-665$.

Kagono, Tadao and Takao Kobayashi. 1994. The Provision of Resources and Barriers to Exit. In Business Enterprise in Japan, ed. Kenichi Imai and Ryutaro Komiya. Cambridge: MIT Press.

Kinder, Donald R. and Cindy D. Kam. 2009. Us against Them: Ethnocentric Foundations of American Opinion. Chicago: University of Chicago Press.

Kinder, Donald R. and D. Roderick Kiewiet. 1981. "Sociotropic Politics: The American Case." British Journal of Political Science 11(2):129-161.

Kobayashi, Tetsuro, Christian Collet, Shanto Iyengar and Kyu S. Hahn. 2015. "Who Deserves Citizenship? An Experimental Study of Japanese Attitudes Toward Immigrant Workers." Social Science Japan Journal 18(1):3-22. 
Koike, Kazuo. 1983. Internal Labor Markets: Workers in Large Firms. In Contemporary Industrial Relations in Japan, ed. Taishiro Shirai. Madison: University of Wisconsin Press.

Koike, Kazuo. 1991. Economics of Work [Shigoto no Keizaigaku]. Tokyo: Toyo Keizai.

Koopmans, Ruud. 2013. "Multiculturalism and Immigration: A Contested Field in CrossNational Comparison." Annual Review of Sociology 39:147-169.

Koshiro, Kazutoshi. 1983. The Quality of Working Life in Japanese Factories. In Contemporary Industrial Relations in Japan, ed. Taishiro Shirai. Madison: University of Wisconsin Press.

McDaniel, Eric L., Irfan Nooruddin and Allyson F. Shortle. 2011. "Divine Boundaries: How Religion Shapes Citizens' Attitudes towards Immigrants." American Politics Research 39(1):205-233.

Ministry of Health, Labour and Welfare. 2016. "Survey on Labour Economic Trends [Rodo Keizai Doko Chosa].".

Moriguchi, Chiaki and Hiroshi Ono. 2006. Japanese Lifetime Employment: A Century's Perspective. In Institutional Change in Japan, ed. Magnus Blomström and Sumner La Croix. Routledge.

Nagayoshi, Kikuko. 2009. "Whose Size Counts? Multilevel Analysis of Japanese AntiImmigrant Attitudes Based on JGSS-2006." JGSS Research Series 6:157-174.

Ottaviano, Gianmarco I. P. and Giovanni Peri. 2012. "Rethinking the Effect of Immigration on Wage." Journal of the European Economic Association 10(1):152-197.

Pempel, T. J. and Keiichi Tsunekawa. 1979. Corporatism Without Labor? The Japanese Anomaly. In Trends Toward Corporatist Intermediation, ed. Phillippe C. Schmitter and Gerhard Lehmbruch. Beverly Hills/London: Sage Publications.

Peri, Giovanni. 2012. "The Effect of Immigration on Productivity: Evidence from U.S. States." Review of Economics and Statistics 94(1):348-358. 
Peri, Giovanni. 2014. "Do Immigrant Workers Depress the Wages of Native Workers." IZA World of Labor.

Quillian, Lincoln. 1995. "Prejudice as a Response to Perceived Group Threat: Population Composition and Anti-Immigrant and Racial Prejudice in Europe." American Sociological Review 60(4):586-611.

Sides, John and Jack Citrin. 2007. "European Opinion About Immigration: The Role of Identities, Interests and Information." British Journal of Political Science 37(3):477504.

Sniderman, Paul M. and Louk Hagendoorn. 2007. When Ways of Life Collide: Multiculturalism $\mathscr{E}$ Its Discontents in the Netherlands. Princeton, NJ: Princeton University Press.

Sniderman, Paul M., Louk Hagendoorn and Markus Prior. 2004. "Predisposing Factors and Situational Triggers: Exclusionary Reactions to Immigrant Minorities." American Political Science Review 98(1):35-49.

Song, Jiyeoun. 2014. Inequality in the Workplace: Labor Market Reform in Japan and Korea. Ithaca: Cornell University Press.

Tingley, Dustin. 2013. "Public Finance and Immigration Preferences: A Lost Connection?" Polity 45(1):4-33.

Valentino, Nicholas A., Ted Brader and Ashley E. Jardina. 2013. "Immigration Opposition Among U.S. Whites: General Ethnocentrism or Media Priming of Attitudes About Latinos?" Political Psychology 34(2):149-166. 


\section{Appendix}

Figure A: Determinants of Individual Preference for Ethnocentrism

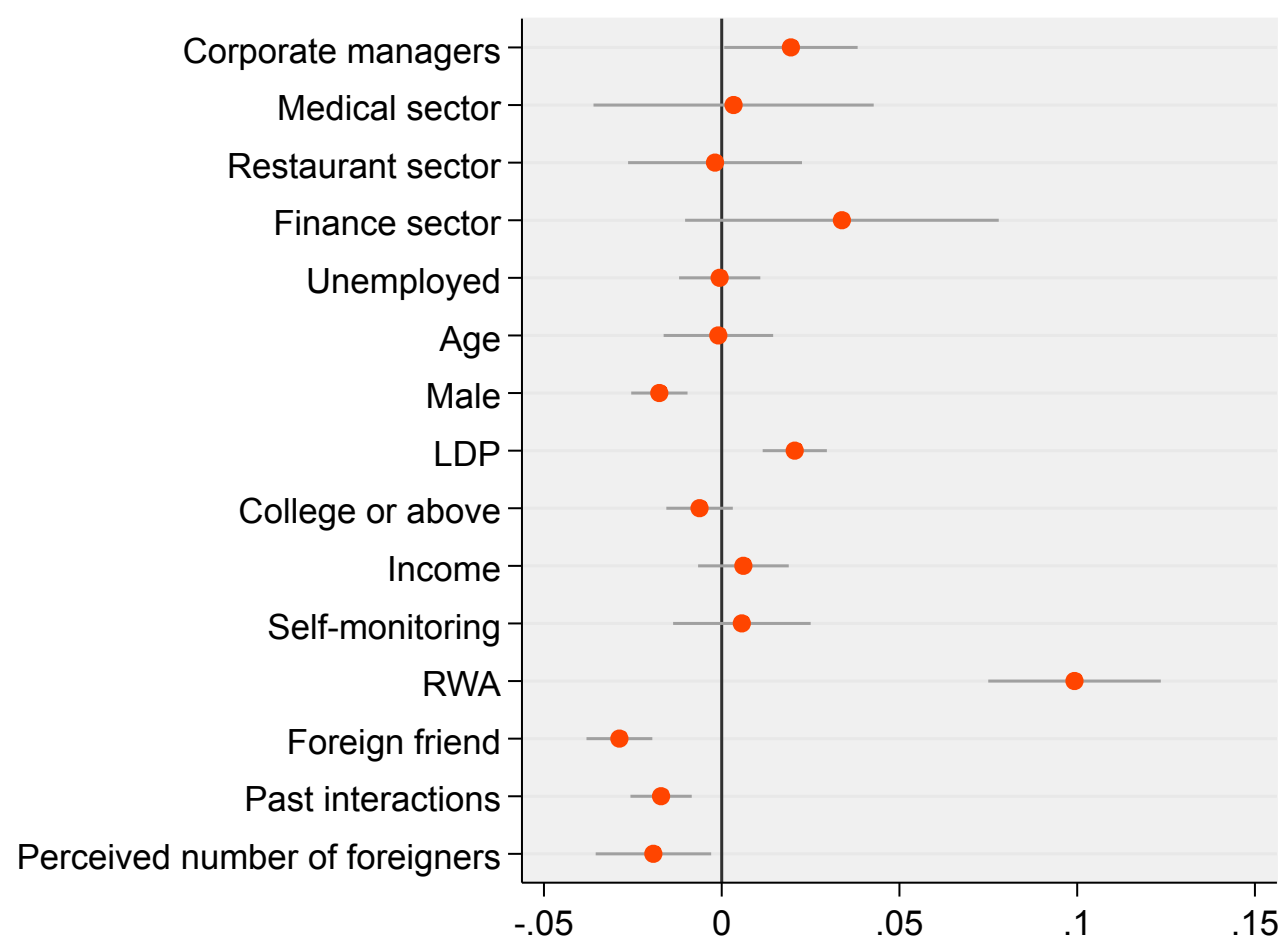

Note: We dropped several respondents from the analysis due to their inconsistent responses. As a result, the current analysis uses 4,179 observations. The horizontal bars indicate $95 \%$ confidence intervals. 